\title{
Analysis of Sentinel Node Biopsy and Clinicopathologic Features as Prognostic Factors in Patients With Atypical Melanocytic Tumors
}

\author{
Andrea Maurichi, MD'; Rosalba Miceli, PhD²; Roberto Patuzzo, MD'; Francesco Barretta, PhD²; Gianfranco Gallino, MD';

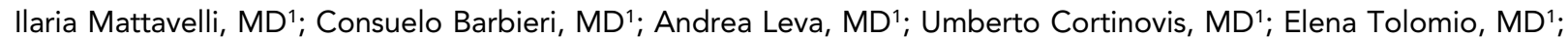 \\ Milena Sant, MD³; Gianpiero Castelli, MD'; Leonardo Zichichi, MD5; Giovanni Pellacani, MD; ; Ignazio Stanganelli, MD; \\ Marco Simonacci, MD ${ }^{8}$; Ausilia Manganoni, MD ; Corrado Del Forno, MD ${ }^{10}$; Gioachino Caresana, MD ${ }^{11}$; \\ Catherine Harwood, MD ${ }^{12}$; Daniele Bergamaschi, $\mathrm{PhD}^{12}$; Konstantinos Lasithiotakis, MD ${ }^{13,14}$; Dorothy Bennett, PhD ${ }^{15}$; \\ Vittoria Espeli, MD ${ }^{16}$; Cristina Mangas, MD ${ }^{16}$; Sandra Leoni Parvex, MD ${ }^{16}$; Barbara Valeri, MD ${ }^{17}$; Mara Cossa, MD ${ }^{17}$; \\ Marta Barisella, MD ${ }^{17}$; Alessandro Pellegrinelli, MD ${ }^{17}$; Claudia Miranda, MD ${ }^{18}$; Andrea Anichini, $\mathrm{PhD}^{19}$; \\ Roberta Mortarini, PhD ${ }^{19}$; Odysseas Zoras, MD' ${ }^{14}$; and Mario Santinami, MD ${ }^{1}$
}

\begin{abstract}
Background: Atypical melanocytic tumors (AMTs) include a wide spectrum of melanocytic neoplasms that represent a challenge for clinicians due to the lack of a definitive diagnosis and the related uncertainty about their management. This study analyzed clinicopathologic features and sentinel node status as potential prognostic factors in patients with AMTs. Patients and Methods: Clinicopathologic and follow-up data of 238 children, adolescents, and adults with histologically proved AMTs consecutively treated at 12 European centers from 2000 through 2010 were retrieved from prospectively maintained databases. The binary association between all investigated covariates was studied by evaluating the Spearman correlation coefficients, and the association between progressionfree survival and all investigated covariates was evaluated using univariable Cox models. The overall survival and progression-free survival curves were established using the Kaplan-Meier method. Results: Median follow-up was 126 months (interquartile range, 104-157 months). All patients received an initial diagnostic biopsy followed by wide $(1 \mathrm{~cm})$ excision. Sentinel node biopsy was performed in 139 patients (58.4\%), 37 (26.6\%) of whom had sentinel node positivity. There were 4 local recurrences, 43 regional relapses,
\end{abstract}

\footnotetext{
${ }^{1}$ Melanoma and Sarcoma Unit, ${ }^{2}$ Medical Statistics, Biometry and Bioinformatics Unit, and ${ }^{3}$ Analytical Epidemiology and Health Impact Unit, Fondazione IRCCS Istituto Nazionale dei Tumori di Milano, Milan, Italy; ${ }^{4}$ Dermatology Unit, Ospedale Umberto I, Siracusa, Italy; ${ }^{5}$ Dermatology Unit, Ospedale S.A. Abate, Trapani, Italy; ${ }^{6}$ University Hospital of Modena, Modena, Italy; ${ }^{7}$ University Hospital of Parma, Parma, Italy; ${ }^{8}$ Dermatology Unit, Hospital of Macerata, Macerata, Italy; ${ }^{9}$ University Hospital of Brescia, Brescia, Italy; ${ }^{10}$ University Hospital of Pavia, Pavia, Italy; ${ }^{11}$ Dermatology Unit, Ospedale Maggiore, Cremona, Italy; ${ }^{12}$ Queen Mary University of London, London, United Kingdom; ${ }^{13}$ York Teaching Hospital NHS Foundation Trust, York, United Kingdom;

${ }^{14}$ University Hospital of Heraklion, Heraklion, Greece; ${ }^{15}$ Molecular and Clinical Sciences Research Institute, St. George's, University of London, London, United Kingdom; ${ }^{16}$ Istituto Oncologico Svizzera Italiana, Ospedale Regionale Bellinzona e Valli, Bellinzona, Switzerland; and ${ }^{17}$ Department of Pathology,

${ }^{18}$ Scientific Directorate, and ${ }^{19}$ Immunobiology of Human Tumors Unit,

Fondazione IRCCS Istituto Nazionale dei Tumori di Milano, Milan, Italy
}

and 8 distant metastases as first events. Six patients (2.5\%) died of disease progression. Five patients who were sentinel node-negative and 3 patients who were sentinel node-positive developed distant metastases. Ten-year overall and progression-free survival rates were $97 \%$ (95\% Cl, 94.9\%-99.2\%) and $82.2 \%$ (95\% Cl, 77.3\%-87.3\%), respectively. Age, mitotic rate $/ \mathrm{mm}^{2}$, mitoses at the base of the lesion, lymphovascular invasion, and 9p21 loss were factors affecting prognosis in the whole series and the sentinel node biopsy subgroup. Conclusions: Age $>20$ years, mitotic rate $>4 / \mathrm{mm}^{2}$, mitoses at the base of the lesion, lymphovascular invasion, and 9p21 loss proved to be worse prognostic factors in patients with ATMs. Sentinel node status was not a clear prognostic predictor.

J Natl Compr Canc Netw 2020;18(10):1327-1336 doi: $10.6004 /$ jnccn.2020.7582

\section{Background}

Cutaneous melanocytic lesions represent a wide spectrum, ranging from benign to overtly malignant. This composite group includes atypical melanocytic tumors (AMTs), mostly occurring in children, adolescents, and young adults, ${ }^{1,2}$ whose biologic behavior and metastatic risk have been controversial and difficult to predict since their initial description by Spitz. ${ }^{1}$ In fact, these tumors have some attributes of malignancy, such as cytologic atypia and mitotic activity, that are considered of insufficient severity to justify a diagnosis of frank malignancy. They were later defined as "borderline melanomas"3,4 or "minimal deviation melanomas"5-7 because of the interpretative problems they presented to physicians in distinguishing them from benign

See JNCCN.org for supplemental online content. 
melanocytic nevi. Smith et $\mathrm{al}^{8}$ and Barnhill et al, ${ }^{9}$ in different analyses, described a kind of Spitz nevus showing atypia and the capability of metastasizing, and they classified this neoplasm as Spitz tumor or atypical Spitz tumor. In subsequent studies, Barnhill ${ }^{10}$ and Elder and $\mathrm{Xu}^{11}$ introduced the term "melanocytic tumor of uncertain malignant potential" or "melanocytic proliferation with indeterminate biologic potential," a descriptive diagnosis generally accompanied by a differential diagnosis, to underline the uncertainties in predicting the clinical behavior. Cerroni et $\mathrm{al}^{12}$ studied a series of melanocytic tumors of uncertain malignant potential and found that the presence of increased mitotic activity, mitoses near the base of the lesion, and an inflammatory reaction were statistically significant parameters unfavorably affecting outcome.

To integrate the conventional morphologic assessment methods for these difficult lesions, some authors proposed sentinel node (SN) status assessment (negative vs positive). ${ }^{13,14}$ The MSLT-1 trial demonstrated the utility of sentinel node biopsy (SNB) as a staging tool and found that SN status was the most powerful prognostic factor in patients with melanoma; this trial was the primary reference study supporting the use of SNB in cutaneous melanoma. ${ }^{15}$ The rationale behind the use of SNB also in AMT was the assumption that the detection of melanocytic cells in the draining regional lymph node basin generally indicates malignancy. ${ }^{14}$

Although some authors found that SN status did not seem to be useful in predicting outcome in atypical spitzoid tumors, a subset of AMT generally occurring in young patients and associated with a good prognosis, other studies emphasized the possible diagnostic and prognostic role of SN status in AMTs, particularly in older patients and nonspitzoid lesions. ${ }^{16-18}$ In different analyses, Gerami et $\mathrm{al}^{19,20}$ and Shen et $\mathrm{al}^{21}$ showed that the integration of molecular and histopathologic data improved the risk assessment of spitzoid tumors, and the use of fluorescence in situ hybridization (FISH) has suggested that specific genomic alterations affect the prognosis of atypical spitzoid tumors. Because the few published analyses of AMT are limited by the small series of cases and/or short follow-up, ${ }^{22,23}$ further characterization of these lesions could be of relevance. We therefore analyzed a large series of patients with a long follow-up to better define the role of SN status as a prognostic factor and to identify other potential clinicopathologic predictors of survival.

\section{Patients and Methods}

\section{Clinicopathologic Features and FISH Analysis}

A total of 238 patients eligible for the study analysis were consecutively treated from 2000 through 2010 at the Istituto Nazionale dei Tumori, Milan, University Hospitals of Brescia, Modena, Parma, and Pavia, and General Hospitals of Cremona, Macerata, Siracusa, and Trapani, all in Italy; Istituto Oncologico Svizzera Italiana, Ospedale Regionale Bellinzona e Valli, Bellinzona, Switzerland; University Hospital of Heraklion, Greece; and Queen Mary University, London, United Kingdom. Clinicopathologic data were retrieved from prospectively maintained databases. All cases were reviewed independently by a pool of dermatopathologists (B.V., M.C., M.B., A.P., S.L.P.), with disagreements resolved through discussion. Cases were subcategorized into 2 groups: spitzoid and nonspitzoid. Spitzoid tumors had a morphology resembling a Spitz tumor (large melanocytic cells, spindle cells and/or epithelioid cells, sharp lateral demarcation of the nests of intraepidermal melanocytes, maturity of cells, and rarity of individual melanocytes high above the basal cell layer). ${ }^{12,24}$ Nonspitzoid tumors included nevoid lesions (resembling a conventional or dysplastic nevus), pigmented epithelioid melanocytomas, deep penetrating nevi, and atypical blue nevi. ${ }^{12}$ Patient age and sex, histologic subtype, tumor thickness, ulceration, mitotic rate $(\mathrm{MR}) / \mathrm{mm}^{2}$, presence of mitotic figures at the base of the lesion (marginal mitoses, within $0.25 \mathrm{~mm}$ of the dermal margin of the lesion), ${ }^{25}$ lymphovascular invasion (LVI), and tumor-infiltrating lymphocytes were recorded for all cases. Morphologic and FISH analysis provided support for a diagnosis of AMT according to the WHO classification criteria. ${ }^{26}$ Two hybridizations were performed: the 4-probe FISH assay targeting 6p25, 6q23, 11q13, and Cep6 was used for the first hybridization, and the 4-probe FISH assay targeting $6 \mathrm{p} 25,9 \mathrm{p} 21,11 \mathrm{q} 13$, and $8 \mathrm{q} 24$ was used for the second. ${ }^{19,20}$ The pool of dermatopathologists, having experience in molecular diagnostics and FISH testing, performed the FISH analyses. A patient was considered to have a positive FISH result based on the criteria and cutoff values used by Gerami et al. ${ }^{19,20,27}$ All patients received an initial diagnostic biopsy followed by wide $(1 \mathrm{~cm})$ excision; SNB was performed in 139 patients $(58.4 \%)$ after the benefits and potential harms had been discussed with them. A total of 95 patients eligible for SNB declined the procedure, whereas 4 did not undergo it due to the presence of comorbidities. Pathologic assessment of SNs was performed according to the EORTC protocol. ${ }^{28}$ Patients with positive SNs were offered completion lymph node dissection (CLND) as additional therapy.

\section{Statistical Methods}

Clinicopathologic characteristics were recorded according to SNB (performed vs not performed) for the whole series of patients, according to $\mathrm{SN}$ status (positive vs negative) in the group undergoing SNB, and according to CLND (performed vs not performed) in the SN-positive group. 
The primary endpoints of the study were overall survival (OS) and progression-free survival (PFS). The OS and PFS curves were estimated using the Kaplan-Meier method ${ }^{29}$ and compared using the log-rank test. Inverse probability of treatment weighting (IPTW) ${ }^{30}$ was applied to groups affected by a selection bias. Standardized mean difference $(\mathrm{SMD})^{31}$ was used to evaluate the balancing of clinicopathologic characteristics. The association between PFS and all investigated covariates was assessed via univariable Cox models.

We applied the elastic net penalization method in the Cox model to perform covariate selection for PFS between all investigated features in the SNB subgroup. ${ }^{32}$ More details on the statistical methods are provided in the supplemental eAppendix 1 (available with this article at JNCCN.org).

\section{Results}

Patient and Disease Characteristics

Clinicopathologic characteristics of the 238 patients with a diagnosis of AMT are summarized in Table 1. Patient age ranged from 3 to 53 years; most AMTs (52.5\%) were diagnosed in young patients (age $\leq 20$ years). The most frequent primary site was the lower limbs (38.2\%). Spitzoid tumors numbered 81 (34\%); nonspitzoid tumors numbered $157(66 \%)$ and included nevoid lesions $(n=89$; $37.4 \%)$, pigmented epithelioid melanocytomas $(n=19$; $8 \%)$, deep penetrating nevi $(n=43 ; 18.1 \%)$, and atypical blue nevi $(n=6 ; 2.5 \%)$. Mitoses at the base of the lesion and LVI were detected in $29 \%$ and $23.5 \%$ of cases, respectively. In $28.6 \%$ of cases, the FISH test showed 9p21 loss.

Clinicopathologic characteristics of the 238 patients according to SNB are summarized in Table 2. The group that underwent SNB and the non-SNB group did not differ with respect to sex, tumor site, tumor thickness, ulceration, $\mathrm{MR} / \mathrm{mm}^{2}$, and tumor-infiltrating lymphocytes. The SNB group differed significantly from the nonSNB group in age ( $5.8 \%$ vs $38.4 \%$ aged $\leq 10$ years; $23.0 \%$ vs $47.5 \%$ aged $11-20$ years; and $71.2 \%$ vs $14.1 \%$ aged $>20$ years). Histologic subtype differed in the SNB group compared with the non-SNB group: $75.5 \%$ of patients who underwent SNB had nonspitzoid tumors and $24.5 \%$ had spitzoid lesions; among those in the non-SNB group, $52.5 \%$ had nonspitzoid tumors and $47.5 \%$ spitzoid lesions. The group that underwent SNB showed significantly higher rates of mitoses at the base of the lesion $33.8 \%$ vs $22.2 \%)$, LVI (28.1\% vs $17.2 \%)$, and 9 p21 loss (33.8\% vs $21.2 \%$ ) than the non-SNB group.

Of the 139 patients that underwent SNB and the 99 that did not, 55 (39.6\%) and 26 (26.3\%), respectively, showed FISH abnormalities. SNB revealed metastatic involvement in 37 (26.6\%) patients. Clinicopathologic characteristics of the 139 patients according to SN status are summarized in supplemental eTable 1. Patients who were SN-positive significantly differed from those who were SN-negative in median number of mitoses $/ \mathrm{mm}^{2}$ (5 vs 2, respectively; SMD, 1.946), presence of mitoses at the base of the lesion $(86.5 \%$ vs $14.7 \%$, respectively; SMD, $2.062)$, and LVI (75.7\% vs $10.8 \%$; SMD, 1.733). Patients who were SN-positive showed significantly higher rates of 9 p21 loss than those who were SN-negative $(45.9 \%$ vs 29.4\%; SMD, 1.587). Of the 37 patients who were $\mathrm{SN}$ positive, 19 (51.4\%) showed FISH abnormalities; 21 (56.7\%) of 37 underwent CLND, among whom 1 (4.8\%) showed further positive non-SNs. Patients who were SNpositive were not offered further treatment (ie, systemic therapies) other than CLND. After IPTW, SMD reached values $<0.1$ for all covariates included in the propensity score model.

\section{Survival Analysis}

Median follow-up was 126 months (interquartile range, 104-157 months). The 10-year OS and PFS were $97 \%$ (95\% CI, 94.9\%-99.2\%) and 82.2\% (95\% CI, 77.3\%-87.3\%), respectively (Figure 1). The group that did not undergo SNB showed slightly better 10-year OS and PFS probabilities than the group that did: $100 \%$ versus $94.9 \%$ (95\% CI, 91.3\%-98.7\%) and $87.8 \%$ (95\% CI, 81.6\%-94.5\%) versus $\quad 77.9 \% \quad(95 \% \quad \mathrm{CI}, \quad 71.0 \%-85.4 \%)$, respectively (Figure 2A, C). Weighted comparisons showed that 10 year OS and PFS were $100 \%$ versus $96.8 \%(95 \% \mathrm{CI}$, 93.3\%-100\%) and $88.5 \%$ (95\% CI, $82.4 \%-95.1 \%)$ versus $84.6 \%$ (95\% CI, $77.4 \%-92.4 \%$ ), respectively; these differences were not statistically significant (Figure 2B, D). Patients who were SN-negative and those who were SN-positive had similar 10-year OS $(96.0 \%$ [95\% CI, 92.3\%-99.9\%] vs $91.9 \%$ [95\% CI, $83.5 \%-100 \%] ; P=.332$ ), whereas patients who were $\mathrm{SN}$-negative showed higher 10 -year PFS (84.2\% [95\% CI, 77.4\%-91.6\%] vs $63.6 \%$ [95\% CI, 49.6\%-81.7\%]; $P=.045$ ) (supplemental eFigure 1).

Supplemental eTable 2 summarizes the clinicopathologic characteristics of patients who were SN-positive according to CLND before and after propensity score weighting. Patients undergoing CLND showed observed 10 -year OS and PFS probabilities similar to those of patients who did not undergo the procedure: $90.5 \%$ (95\% CI, $78.8 \%-100 \%$ ) versus $93.8 \%$ (95\% CI, $82.6 \%-100 \%$ ) and 61.0 (95\% CI, $43.0 \%-86.3 \%$ ) versus $67.0 \%$ (95\% CI, $46.9 \%-95.8 \%$ ), respectively (supplemental eFigure $2 \mathrm{~A}, \mathrm{C}$ ). After weighting, the 10-year OS and PFS probabilities were $85.8 \%$ (95\% CI, $65.6 \%-100 \%$ ) versus $97.9 \%$ (95\% CI, $89.0 \%-100 \%)$ and $64.9 \%(95 \% \mathrm{CI}, 39.6 \%-100 \%)$ versus $61.0 \%$ (95\% CI, 35.7\%-100\%), respectively (supplemental eFigure 2B, D).

There were 4 local recurrences, 43 regional recurrences, and 8 distant metastases as first events. Six patients died as a result of disease progression. Of the 
Table 1. Clinicopathologic Characteristics

\begin{tabular}{|c|c|}
\hline Characteristic & n (\%) \\
\hline Total & $238(100)$ \\
\hline \multicolumn{2}{|l|}{ Age } \\
\hline$\leq 10 y$ & $46(19.3)$ \\
\hline $11-20 y$ & 79 (33.2) \\
\hline$>20 y$ & $113(47.5)$ \\
\hline \multicolumn{2}{|l|}{ Sex } \\
\hline Female & $122(51.3)$ \\
\hline Male & $116(48.7)$ \\
\hline \multicolumn{2}{|l|}{ Tumor site } \\
\hline Head and neck & $78(32.8)$ \\
\hline Upper limbs & $43(18.1)$ \\
\hline Trunk & $26(10.9)$ \\
\hline Lower limbs & $91(38.2)$ \\
\hline \multicolumn{2}{|l|}{ Histologic subtype } \\
\hline Spitzoid & $81(34.0)$ \\
\hline Nonspitzoida & $157(66.0)$ \\
\hline \multicolumn{2}{|c|}{ Tumor thickness, mm } \\
\hline Median (IQRE) & $2.34(2.20-2.49)$ \\
\hline \multicolumn{2}{|l|}{ Ulceration } \\
\hline Absent & $225(94.5)$ \\
\hline Present & $13(5.5)$ \\
\hline \multicolumn{2}{|l|}{ Mitosis, per $\mathrm{mm}^{2}$} \\
\hline Median (IQRE) & $2(1-4)$ \\
\hline \multicolumn{2}{|c|}{ Mitosis at the base of the lesion } \\
\hline Absent & $169(71.0)$ \\
\hline Present & $69(29.0)$ \\
\hline \multicolumn{2}{|c|}{ Lymphovascular invasion } \\
\hline Absent & $182(76.5)$ \\
\hline Present & $56(23.5)$ \\
\hline \multicolumn{2}{|c|}{ Tumor-infiltrating lymphocytes } \\
\hline Absent & $83(34.9)$ \\
\hline Brisk & 79 (33.2) \\
\hline Nonbrisk & $76(31.9)$ \\
\hline \multicolumn{2}{|l|}{ FISH test $6 p 25$} \\
\hline Negative & $209(87.8)$ \\
\hline Positive & $29(12.2)$ \\
\hline \multicolumn{2}{|c|}{ FISH test $6 q 23 / \mathrm{Cep} 6$} \\
\hline Negative & $231(97.1)$ \\
\hline Positive & $7(2.9)$ \\
\hline \multicolumn{2}{|c|}{ FISH test $6 p 25 /$ Cep 6} \\
\hline Negative & $233(97.9)$ \\
\hline Positive & $5(2.1)$ \\
\hline
\end{tabular}

(continued)

\section{Table 1. Clinicopathologic Characteristics (cont.)}

\begin{tabular}{|lr|}
\hline Characteristic & $\mathbf{n}(\%)$ \\
\hline \begin{tabular}{l} 
FISH test 11q13 \\
\hline Negative
\end{tabular} & $211(88.7)$ \\
\hline Positive & $27(11.3)$ \\
\hline FISH test 9p21 & $170(71.4)$ \\
\hline Negative & $68(28.6)$ \\
\hline Positive & $234(98.3)$ \\
\hline FISH test 8q24 & $4(1.7)$ \\
\hline Negative & $102(42.9)$ \\
\hline Positive & $37(15.5)$ \\
\hline Sentinel node biopsy & $99(41.6)$ \\
\hline Negative & \\
\hline Positive & \\
\hline Not performed & \\
\hline
\end{tabular}

Abbreviation: FISH, fluorescence in situ hybridization; IQRE, interquartile range extremes.

aNevoid, deep penetrating nevus, or atypical blue nevus.

patients who developed regional recurrences, 34 (79.1\%) had not undergone SNB, 6 (13.9\%) underwent SNB and were SN-positive, and $3(7 \%)$ underwent SNB and were SN-negative. Of the 51 patients who developed regional and distant metastases, 40 (78.4\%) showed FISH abnormalities. Five patients who were SN-negative and 3 who were SN-positive, all belonging to the nonspitzoid group, developed distant metastases beyond the regional nodal basin; of these patients, 4 developed distant metastases after regional recurrence and 4 had distant spread in the absence of previous regional node metastases. The 8 patients who developed distant disease -6 of whom died of their disease- - had an age range from 28 to 42 years; the histologic diagnosis was nevoid lesion in 6 cases, deep penetrating nevus in 1 case, and atypical blue nevus in 1 case. Three patients developed another malignancy, and 1 died of causes unrelated to AMT.

In univariable analysis of the whole series, age $\leq 10$ versus $>20$ years and age $11-20$ versus $>20$ years; MR $\geq 4 / \mathrm{mm}^{2}$; mitoses at the base of the lesion; LVI; and 9p21 loss (all $P<.001$ ) were strongly associated with a worse PFS, whereas SN status $(P=.024)$ was mildly associated. All of the strongly associated variables were observed in the group in which SNB was performed (Table 3). The hazard ratio of PFS increased from 0 to 4 for MR and then reached a plateau, whereas for age, it increased up to 30 years and then decreased. Among the 55 patients with recurrences, 37 (67.3\%) had $\mathrm{MR} \geq 4,35$ (63.6\%) had mitoses at the base of the lesion, $33(60 \%)$ had LVI, and 34 (61.8\%) showed 9p21 loss. Of the 183 patients without recurrences 21 (11.5\%) had MR $\geq 4,19$ (10.4\%) had mitoses at the base of the lesion, 24 (13.1\%) had LVI, and 26 
Table 2. Clinicopathologic Characteristics According to SNB, Before and After Propensity Score Weighting

Unweighted Statistics

SNB Not Performed SNB Performed
n (\%)

Total

Age

$\leq 10$ y

$11-20 y$

$>20 y$

Sex

Female

Male

Tumor site

Head and neck

Upper limbs

Trunk

Lower limbs

Histologic subtype

Spitzoid

Nonspitzoid ${ }^{a}$

Tumor thickness, $\mathrm{mm}$

Median (IQRE)

Ulceration

\section{Absent}

Present

Mitosis, per $\mathrm{mm}^{2}$

Median (IQRE)

Mitosis at the base of the lesion

Absent

Present

Lymphovascular invasion

Absent

Present

Tumor-infiltrating lymphocytes

Absent

Brisk

Nonbrisk

FISH test 6 p25

$$
\begin{aligned}
& \text { Negative } \\
& \text { Positive }
\end{aligned}
$$

FISH test 6q23/Cep 6

Negative

Positive

FISH test 6p25/Cep 6

$$
\begin{aligned}
& \text { Negative } \\
& \text { Positive }
\end{aligned}
$$

99 (41.6)

$38(38.4)$

47 (47.5)

$14(14.1)$

51 (51.5)

48 (48.5)

$34(34.3)$

17 (17.2)

$10(10.1)$

38 (38.4)

47 (47.5)

$52(52.5)$

$2.32(2.21-2.50)$

94 (94.9)

$5(5.1)$

$$
2(1-2)
$$

77 (77.8)

22 (22.2)

82 (82.8)

17 (17.2)

38 (38.4)

29 (29.3)

32 (32.3)

89 (89.9)

10 (10.1)

$96(97.0)$

3 (3.0)

97 (98.0)

2 (2.0)
139 (58.4)

8 (5.8)

32 (23.0)

99 (71.2)

71 (51.1)

68 (48.9)

44 (31.7)

26 (18.7)

$16(11.5)$

53 (38.1)

$34(24.5)$

105 (75.5)

2.35 (2.22-2.49)

131 (94.2)

$8(5.8)$

92 (66.2)

47 (33.8)

100 (71.9)

39 (28.1)

45 (32.4)

50 (36.0)

44 (31.7)

$120(86.3)$

19 (13.7)

135 (97.1)

$4(2.9)$

136 (97.8)

$3(2.2)$
0.026

$13.1(13.6)$

Weighted Statistics

SMD

SNB Not Performed SNB Performed

n (\%)

$96.4(50.8)$

37.2 (38.6)

$46.1(47.8)$

13.1 (13.6)

$50.3(52.2)$

46.1 (47.8)

0.230

0.049

32.7 (33.9)

16.5 (17.1)

$10.0(10.4)$

37.2 (38.6)

$46.3(48.0)$

$50.1(52.0)$

0.056

0.031

0.218

$2.32(2.20-2.50)$

0.260

$91.4(94.8)$

$5(5.2)$

$$
2(1-2)
$$

75.4 (78.2)

0.262

$21(21.8)$

0.262

79.4 (82.4)

17 (17.6)

0.155

37.3 (38.7)

27.4 (28.5)

31.6 (32.8)

0.110

\begin{tabular}{rr} 
& $86.6(89.9)$ \\
\hline & $9.8(10.1)$ \\
\hline
\end{tabular}

93.4 (96.9)

$3.0(3.1)$

0.136
94.4 (97.9)

$2.0(2.1)$
$96.1(49.2)$

0.078

SMD

0.005

37.5 (39.0)

$48.4(50.4)$

$10.2(10.6)$

50.9 (53)

45.2 (47)

0.067

$33.8(35.2)$

$17.1(17.8)$

$7.2(7.5)$

$38.0(39.5)$

0.016

$44.8(46.6)$

$51.3(53.4)$

$2.35(2.25-2.48)$

0.007

0.021

$91.6(95.3)$

4.5 (4.7)

$2(1-2)$

0.002

0.001

75.2 (78.3)

$20.9(21.7)$

$79.1(82.3)$

$17.0(17.7)$

$32.1(33.4)$

$33.2(34.5)$

$30.8(32.1)$

0.072

$88.4(92.0)$

7.7 (8.0)

93.4 (97.2)

2.7 (2.8)

0.105

0.141

0.14

0.001

.

141

0.072

0.07

0.136

$92.2(95.9)$

$3.9(4.1)$ 


\begin{tabular}{|c|c|c|c|c|c|c|}
\hline & \multicolumn{3}{|c|}{ Unweighted Statistics } & \multicolumn{3}{|c|}{ Weighted Statistics } \\
\hline & $\begin{array}{c}\text { SNB Not Performed } \\
n(\%)\end{array}$ & $\begin{array}{c}\text { SNB Performed } \\
\text { n (\%) }\end{array}$ & SMD & $\begin{array}{c}\text { SNB Not Performed } \\
\text { n (\%) }\end{array}$ & $\begin{array}{l}\text { SNB Performed } \\
n(\%)\end{array}$ & SMD \\
\hline FISH test $11 q 13$ & & & 0.680 & & & 0.030 \\
\hline Negative & 89 (89.9) & $122(87.8)$ & & $86.6(89.9)$ & $85.5(88.9)$ & \\
\hline Positive & $10(10.1)$ & $17(12.2)$ & & $9.8(10.1)$ & $10.6(11.1)$ & \\
\hline FISH test 9p21 & & & 0.285 & & & 0.001 \\
\hline Negative & $78(78.8)$ & $92(66.2)$ & & 75.4 (78.2) & $75.2(78.3)$ & \\
\hline Positive & $21(21.2)$ & $47(33.8)$ & & $21(21.8)$ & $20.9(21.7)$ & \\
\hline FISH test $8 q 24$ & & & 0.092 & & & 0.114 \\
\hline Negative & $97(98.0)$ & $137(98.6)$ & & $94.4(97.9)$ & $92.7(96.5)$ & \\
\hline Positive & $2(2.0)$ & $2(1.4)$ & & $2.0(2.1)$ & $3.4(3.5)$ & \\
\hline SNB & & & - & & & - \\
\hline Negative & $0(0.0)$ & $102(73.4)$ & & $0(0)$ & $77.6(80.7)$ & \\
\hline Positive & $0(0.0)$ & $37(26.6)$ & & $0(0)$ & $18.5(19.3)$ & \\
\hline Not performed & $99(100)$ & $0(0.0)$ & & $96.4(100)$ & $0(0)$ & \\
\hline
\end{tabular}

Abbreviations: AMT, atypical melanocytic tumor; FISH, fluorescence in situ hybridization; IQRE, interquartile range extremes; SMD, standardized mean difference; SNB, sentinel node biopsy.

aNevoid, deep penetrating nevus, or atypical blue nevus.

(14.2\%) showed 9p21 loss. After IPTW, SMD reached values $<0.1$ for all covariates included in the PS model (data not shown).

\section{Predictive Covariate Selection}

The elastic net penalized Cox model selection procedure led to the selection of higher MR, mitoses at the base of the lesion, LVI, and 9p21 loss as the most relevant covariates for PFS prediction. The sparsity of the events and the high correlation issue in our series prevented us from developing a reliable predictive model based on the selected variables.

\section{Discussion}

We found a positive SN rate of $26.6 \%$, in line with data reported in other studies in which a higher proportion of positive SNs was observed in patients with AMTs compared with those with conventional melanomas. ${ }^{15,33}$ However, our study did not clearly show that SN status was a predictor of OS. Although most of the variables associated with a worse prognosis ( $\mathrm{MR} / \mathrm{mm}^{2} \geq 4$, mitoses at the base of the lesion, LVI, and 9p21 loss) were prevalent in patients who were SN-positive and could be considered to identify individuals eligible for SNB, in our analyses, SN status did not seem to provide the same important prognostic information for AMT as observed in cutaneous melanoma. ${ }^{15}$ Because our findings are not strong enough to mandate SNB for AMT currently, ultrasound imaging could be an alternative approach during follow-up. ${ }^{34}$
However, the number of positive SNs in our series was small, and further analyses of larger series of patients are needed to better evaluate the prognostic role of SN status.

Previous studies in small series with a shorter followup focusing on the role of SN status yielded controversial results. Busam et $\mathrm{al}^{35}$ reported that children and teenagers with spitzoid AMTs and positive SNs had a less aggressive clinical course than patients with SN-positive melanoma. Ghazi et al, ${ }^{16}$ in a study of patients with AMTs with a median age of 24 years, showed that lymph node assessment did not predict the outcome of spitzoid AMTs. Gamblin et $\mathrm{al}^{36}$ and Murali et $\mathrm{al}^{37}{ }^{37}$ in different analyses, reached the opposite conclusion, arguing that SNB could offer a means for assessing the metastatic potential of spitzoid AMTs and represented an adjunct tool in patient management.

In our series, the 6 deaths as a result of disease progression confirmed that AMT should be considered a provisional diagnosis pending molecular and genetic analyses, expert review, and outcome; all our data were used to predict the likelihood of melanoma in these patients. Our analysis showed that $\mathrm{MR} \geq 4$ and the presence of mitoses at the base of the lesion correlated with a worse prognosis. These factors seemed to be indicators of a more aggressive clinical behavior and to be associated with a higher probability of distant metastatic spread beyond the regional nodal basin. Mitosis should be taken into consideration as a prognostic factor in AMTs, and its relevance should be carefully evaluated in clinical decision-making. 
A

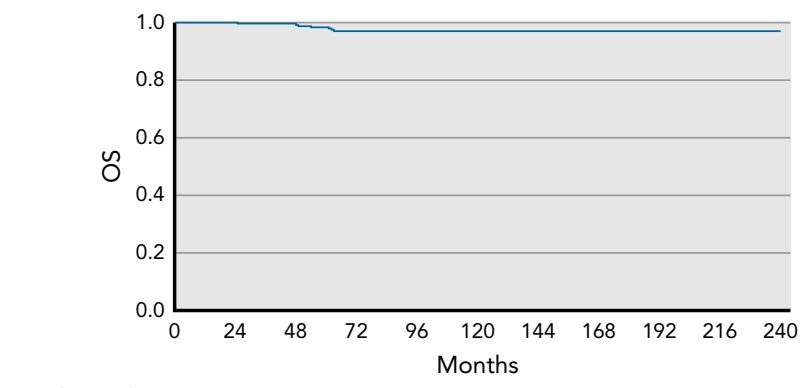

Number at risk:

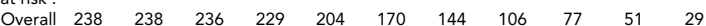

B

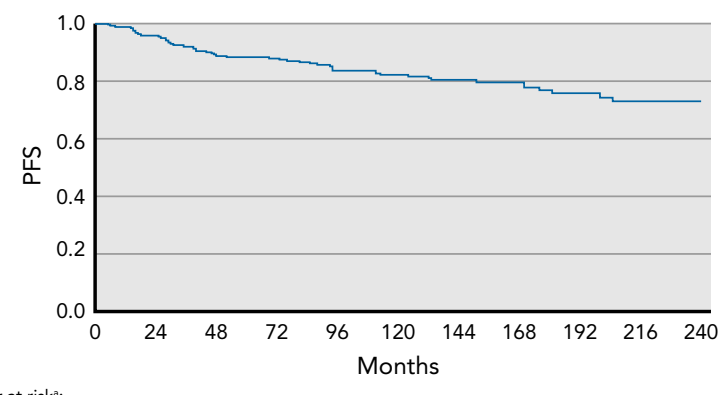

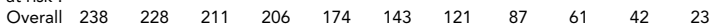

Figure 1. Atypical melanocytic tumors. Kaplan-Meier curves for (A) OS and (B) PFS in the whole series. Abbreviations: OS, overall survival; PFS, progression-free survival.

aNumber of patients at risk for an event.

Our data are in line with various previous reports in which these variables were heavily weighted for their diagnostic and prognostic significance. Cerroni et al ${ }^{12}$ identified only 3 parameters that were statistically different between 2 groups of AMTs with favorable and unfavorable behavior based on clinical followup: high MR, mitoses near the base of the lesion, and an inflammatory infiltrate. In a more recent study,

\section{A}

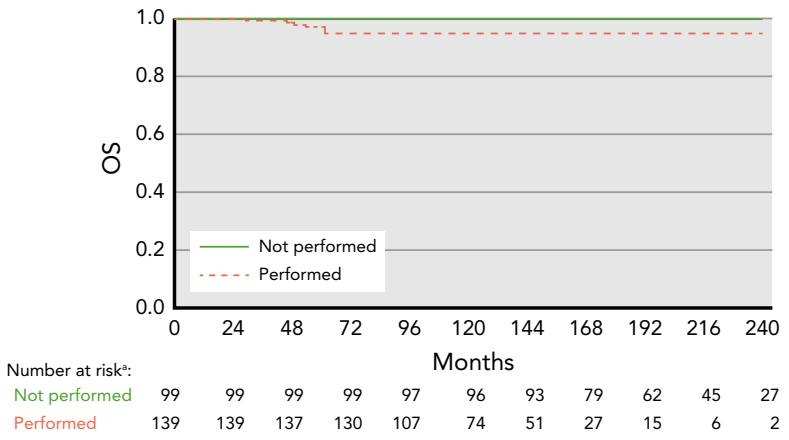

C

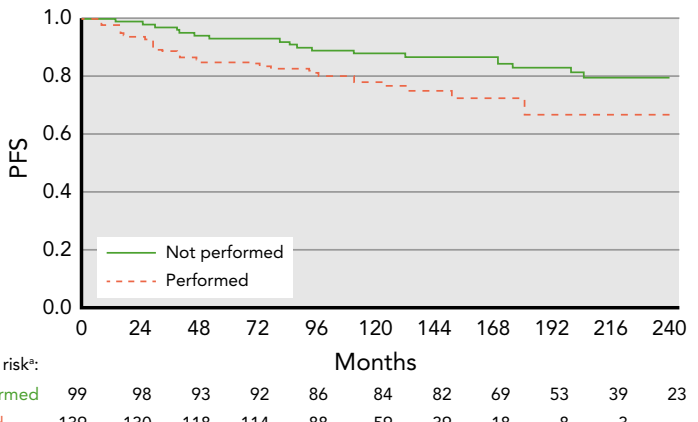

Gerami et $\mathrm{al}^{38}$ assessed interobserver agreement in diagnosis by 13 expert dermatopathologists for 75 atypical spitzoid tumors and confirmed that frequent mitoses and deep mitoses were histomorphologic features that correlated with disease progression. In our analysis, no statistically significant association was found between an inflammatory infiltrate and patient outcome.
B

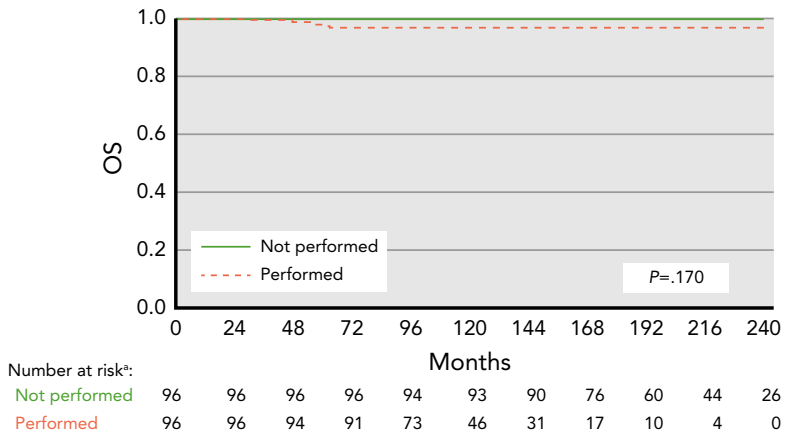

D

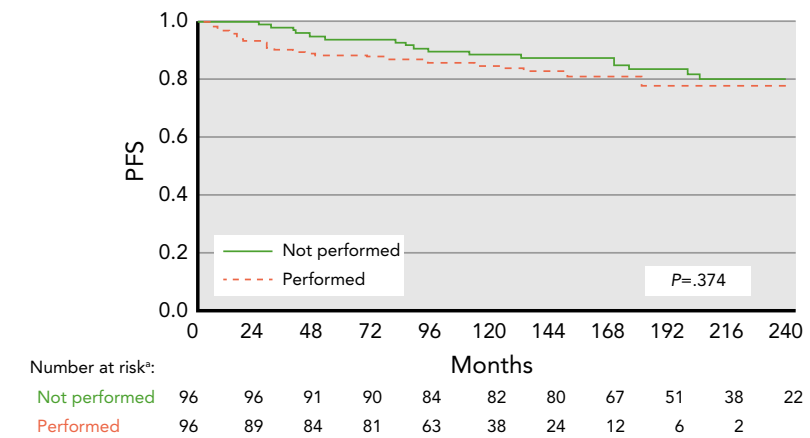

Figure 2. Unweighted and weighted Kaplan-Meier curves for (A, B) OS and (C, D) PFS according to sentinel node biopsy (performed or not performed).

Abbreviations: OS, overall survival; PFS, progression-free survival; SNB, sentinel node biopsy.

a' Weighted number of patients at risk for an event (rounded to the integer in the weighted analysis). 
Table 3. Results of Univariable Cox Model Analysis for Progression-Free Survival

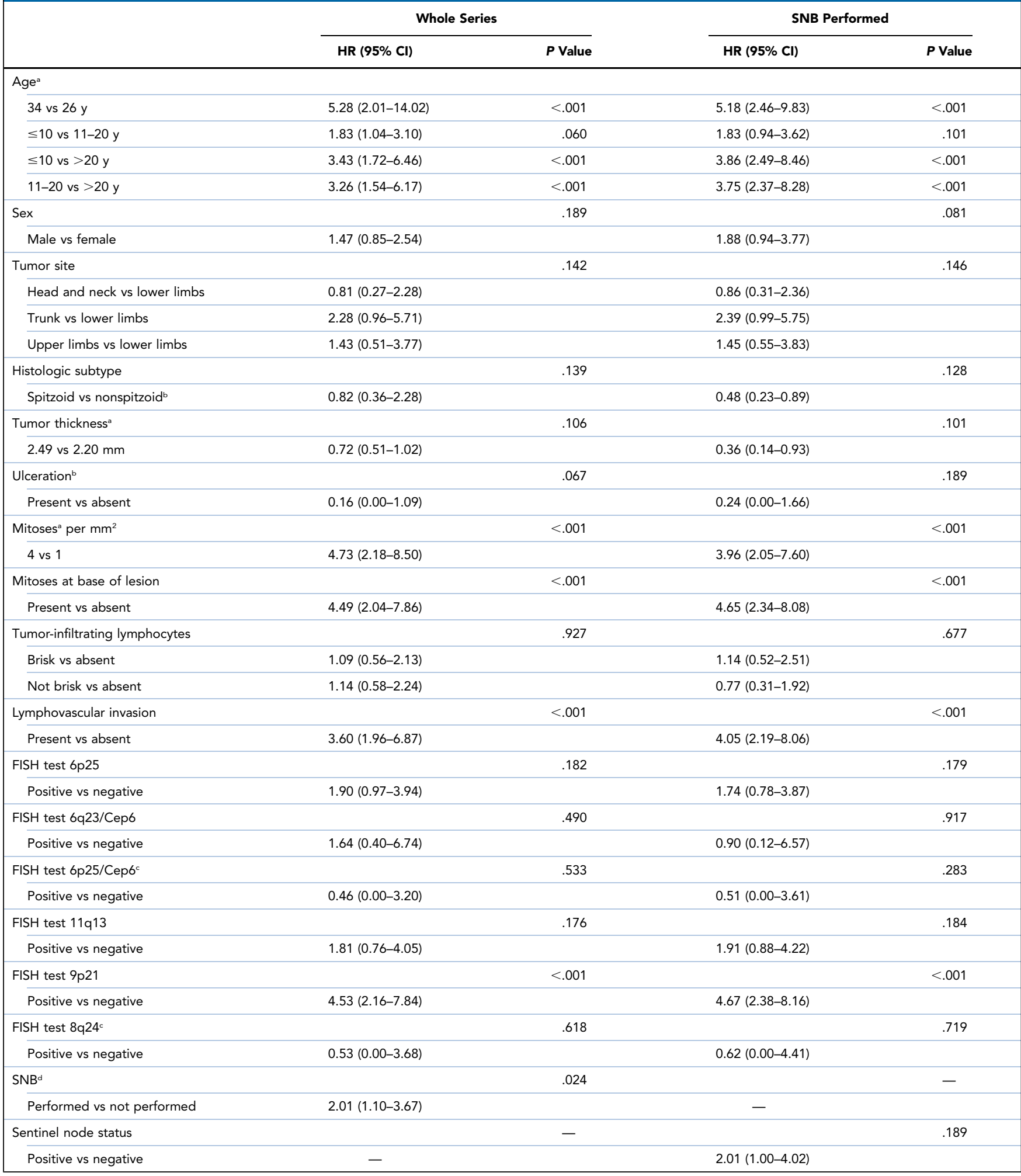

$P$ values were calculated using the Wald test.

Abbreviations: FISH, fluorescence in situ hybridization; HR, hazard ratio; SNB, sentinel node biopsy.

aModeled as restricted cubic spline. Reference values are third and first quartiles.

bNevoid, deep penetrating nevus, or atypical blue nevus.

'Estimated with Firth's penalized model.

Inverse probability treatment weighted comparison. 
Our study also provides evidence that LVI was associated with shorter survival. We found that the tumorassociated lymphatic network constituted a potential criterion in the selection of high-risk patients who should be candidates for careful follow-up. Another investigation into the prognostic role of LVI in AMT conducted by Abraham et $\mathrm{al}^{39}$ in a small number of lesions related this parameter to a poorer prognosis.

Furthermore, our findings showed that the groups of younger patients (aged $<10$ years and $11-20$ years) with AMT had a longer survival. Spatz et $\mathrm{al}^{40}$ analyzed various parameters, including age, to define a grading system for risk stratification of atypical Spitz tumors. They found that diagnosis at age $>10$ years carried a likelihood ratio $>1.50$, so this variable was used for the grading system. The low rate of local recurrences $(1.7 \%)$ in our series confirmed that wide surgical excision with $1-\mathrm{cm}$ margins was adequate to control local recurrence. Ludgate et al, ${ }^{41}$ in another study of 67 patients with atypical Spitz tumors, observed 1 local recurrence and recommended 1-cm excision margins to prevent local recurrences.

Finally, in our analysis, AMTs were classified into specific risk categories based on the cytogenetic changes determined by FISH. In the survival analysis, we found that 9p21 loss was associated with a higher risk of distant spread. Gerami et $\mathrm{al}^{20}$ evaluated 2 small subgroups of high-risk melanocytic neoplasms in children-including spitzoid melanomas, atypical Spitz tumors with chromosomal copy number changes, and conventional melanomas-and found that the presence of a homozygous deletion of $9 \mathrm{p} 21$ and a positive SNB in atypical Spitz tumors was associated with a higher risk of systemic metastasis and death. Another analysis by Gerami et $\mathrm{al}^{19}$ showed that also the presence of $6 \mathrm{p} 25$ and/or 11 113 gain was significantly associated with tumor progression beyond the SN when compared with FISHnegative tumors. In our series, $6 \mathrm{p} 25$ and $11 \mathrm{q} 13$ gains were not associated with a higher risk of distant spread. Additional techniques to assess molecular genetic alterations, such as comparative genomic hybridization, next-generation sequencing, microRNA and mRNA analysis, and mass spectrometric imaging, will help improve the differential diagnosis and clinical management of AMTs in the near future. ${ }^{42}$

\section{Conclusions}

Our findings showed that age $>20$ years, $M R \geq 4$, mitoses at the base of the lesion, LVI, and FISH evidence of 9p21 loss were all independent predictors of more aggressive tumor behavior. SN status did not prove to be a clear prognostic factor. Our retrospective analysis may contribute to establishing a practical framework for managing patients with AMTs in which clinical decisions are supported by identifying at-risk patients who may benefit from more frequent and longer-term follow-up.

\section{Acknowledgments}

The authors thank Marije de Jager for help with the English language, and acknowledge Antonio Florita and Elena Morittu for assistance in manuscript submission.

Submitted September 16; 2019; accepted for publication April 28, 2020.

Author contributions: Study concept: Maurichi, Miceli, Anichini, Mortarini, Santinami. Data acquisition: Patuzzo, Gallino, Mattavelli, Barbieri, Leva, Cortinovis, Tolomio, Sant, Castelli, Zichichi, Pellacani, Stanganelli, Simonacci, Manganoni, Del Forno, Caresana, Harwood, Lasithiotakis, Espeli, Mangas, Zoras. Data analysis and interpretation: Maurichi, Patuzzo, Leoni Parvex, Valeri, Cossa, Barisella, Pellegrinelli, Santinami. Statistical analysis: Miceli, Barretta. Manuscript preparation: Maurichi, Miceli, Barretta, Bergamaschi, Bennett, Miranda. Manuscript review and editing: All authors.

Disclosures: The authors have disclosed that they have not received any financial considerations from any person or organization to support the preparation, analysis, results, or discussion of this article.

Correspondence: Andrea Maurichi, MD, Melanoma and Sarcoma Unit Fondazione IRCCS Istituto Nazionale dei Tumori di Milano, Via Giacomo Venezian 1, 20133 Milan, Italy. Email: andrea.maurichi@istitutotumori.mi.it

\section{References}

1. Spitz S. Melanomas of childhood. Am J Pathol 1948;24:591-609.

2. Kernen JA, Ackerman LV. Spindle cell nevi and epithelioid cell nevi (socalled juvenile melanomas) in children and adults: a clinicopathological study of 27 cases. Cancer 1960;13:612-625.

3. Reed RJ, Ichinose H, Clark WH Jr, et al. Common and uncommon melanocytic nevi and borderline melanomas. Semin Oncol 1975;2:119-147.

4. Sagebiel RW. Histopathology of borderline and early malignant melanomas. Am J Surg Pathol 1979;3:543-552.

5. Muhlbauer JE, Margolis RJ, Mihm MC Jr, et al. Minimal deviation melanoma: a histologic variant of cutaneous malignant melanoma in its vertical growth phase. J Invest Dermatol 1983;80(6 Suppl): 63s-65s.

6. Phillips ME, Margolis RJ, Merot Y, et al. The spectrum of minimal deviation melanoma: a clinicopathologic study of 21 cases. Hum Pathol 1986;17:796-806.

7. Reed RJ. Minimal deviation melanoma. Hum Pathol 1990;21:1206-1211.

8. Smith KJ, Barrett TL, Skelton HG III, et al. Spindle cell and epithelioid cell nevi with atypia and metastasis (malignant Spitz nevus). Am J Surg Pathol 1989;13:931-939.

9. Barnhill RL, Argenyi ZB, From L, et al. Atypical Spitz nevi/tumors: lack of consensus for diagnosis, discrimination from melanoma, and prediction of outcome. Hum Pathol 1999;30:513-520.

10. Barnhill RL. Malignant melanoma. In: Barnhill RL, Piepkorn M, Busam KJ eds. Pathology of Melanocytic Nevi and Malignant Melanoma. 2nd ed. New York, NY: Springer; 2004:238-356.

11. Elder DE, Xu X. The approach to the patient with a difficult melanocytic lesion. Pathology 2004;36:428-434.

12. Cerroni L, Barnhill R, Elder D, et al. Melanocytic tumors of uncertain malignant potential: results of a tutorial held at the XXIX Symposium of the International Society of Dermatopathology in Graz, October 2008. Am J Surg Pathol 2010;34:314-326.

13. Kelley SW, Cockerell CJ. Sentinel lymph node biopsy as an adjunct to management of histologically difficult to diagnose melanocytic lesions: a proposal. J Am Acad Dermatol 2000;42:527-530.

14. Lohmann CM, Coit DG, Brady MS, et al. Sentinel lymph node biopsy in patients with diagnostically controversial spitzoid melanocytic tumors. Am J Surg Pathol 2002;26:47-55. 
15. Morton DL, Thompson JF, Cochran AJ, et al. Final trial report of sentinelnode biopsy versus nodal observation in melanoma. N Engl J Med 2014; 370:599-609.

16. Ghazi B, Carlson GW, Murray DR, et al. Utility of lymph node assessment for atypical spitzoid melanocytic neoplasms. Ann Surg Oncol 2010;17: 2471-2475.

17. Sepehr A, Chao E, Trefrey B, et al. Long-term outcome of Spitz-type melanocytic tumors. Arch Dermatol 2011;147:1173-1179.

18. Caracò C, Mozzillo N, Di Monta G, et al. Sentinel lymph node biopsy in atypical Spitz nevi: is it useful? Eur J Surg Oncol 2012;38:932-935.

19. Gerami P, Scolyer RA, Xu X, et al. Risk assessment for atypical spitzoid melanocytic neoplasms using FISH to identify chromosomal copy number aberrations. Am J Surg Pathol 2013;37:676-684.

20. Gerami P, Cooper C, Bajaj S, et al. Outcomes of atypical Spitz tumors with chromosomal copy number aberrations and conventional melanomas in children. Am J Surg Pathol 2013;37:1387-1394.

21. Shen L, Cooper C, Bajaj S, et al. Atypical Spitz tumors with 6q23 deletions: a clinical, histological, and molecular study. Am J Dermatopathol 2013;35: 804-812.

22. Massi D, Tomasini C, Senetta R, et al. Atypical Spitz tumors in patients younger than 18 years. J Am Acad Dermatol 2015;72:37-46.

23. Lee CY, Sholl LM, Zhang B, et al. Atypical spitzoid neoplasms in childhood: a molecular and outcome study. Am J Dermatopathol 2017;39:181-186.

24. Paniago-Pereira C, Maize JC, Ackerman AB. Nevus of large spindle and/or epithelioid cells (Spitz's nevus). Arch Dermatol 1978;114:1811-1823.

25. Crotty KA. Spitz naevus: histological features and distinction from malignant melanoma. Australas J Dermatol 1997;38(S1):S49-53.

26. Elder DE, Massi D, Scolyer RA, et al, eds. WHO Classification of Skin Tumours, 4th ed. Vol. 11. Lyon, France: IARC; 2018.

27. Gerami P, Wass A, Mafee M, et al. Fluorescence in situ hybridization for distinguishing nevoid melanomas from mitotically active nevi. Am J Surg Pathol 2009;33:1783-1788.

28. Cook MG, Massi D, Szumera-Ciećkiewicz A, et al. An updated European Organisation for Research and Treatment of Cancer (EORTC) protocol for pathological evaluation of sentinel lymph nodes for melanoma. Eur J Cancer 2019:114:1-7.

29. Schemper M, Smith TL. A note on quantifying follow-up in studies of failure time. Control Clin Trials 1996;17:343-346.
30. Austin PC, Stuart EA. Moving towards best practice when using inverse probability of treatment weighting (IPTW) using the propensity score to estimate causal treatment effects in observational studies. Stat Med 2015 34:3661-3679.

31. Flury BK, Riedwyl H. Standard distance in univariate and multivariate analysis. Am Stat 1986;40:249-251.

32. Zou H, Hastie T. Regularization and variable selection via the elastic net. J R Stat Soc Series B Stat Methodol 2005;67:301-320.

33. Hung $T$, Piris A, Lobo A, et al. Sentinel lymph node metastasis is not predictive of poor outcome in patients with problematic spitzoid melanocytic tumors. Hum Pathol 2013;44:87-94.

34. Hayes AJ, Moskovic E, O'Meara K, et al. Prospective cohort study of ultrasound surveillance of regional lymph nodes in patients with intermediate-risk cutaneous melanoma. Br J Surg 2019;106:729-734.

35. Busam KJ, Murali R, Pulitzer M, et al. Atypical spitzoid melanocytic tumors with positive sentinel lymph nodes in children and teenagers, and comparison with histologically unambiguous and lethal melanomas. Am J Surg Pathol 2009;33:1386-1395.

36. Gamblin TC, Edington H, Kirkwood JM, et al. Sentinel lymph node biopsy for atypical melanocytic lesions with spitzoid features. Ann Surg Oncol 2006;13:1664-1670.

37. Murali R, Sharma RN, Thompson JF, et al. Sentinel lymph node biopsy in histologically ambiguous melanocytic tumors with spitzoid features (socalled atypical spitzoid tumors). Ann Surg Oncol 2008;15:302-309.

38. Gerami P, Busam K, Cochran A, et al. Histomorphologic assessment and interobserver diagnostic reproducibility of atypical spitzoid melanocytic neoplasms with long-term follow-up. Am J Surg Pathol 2014;38:934-940.

39. Abraham RM, Karakousis G, Acs G, et al. Lymphatic invasion predicts aggressive behavior in melanocytic tumors of uncertain malignant potential (MELTUMP). Am J Surg Pathol 2013;37:669-675.

40. Spatz A, Calonje E, Handfield-Jones S, et al. Spitz tumors in children: a grading system for risk stratification. Arch Dermatol 1999;135:282-285.

41. Ludgate MW, Fullen DR, Lee J, et al. The atypical Spitz tumor of uncertain biologic potential: a series of 67 patients from a single institution. Cancer 2009;115:631-641.

42. Hillen LM, Van den Oord J, Geybels MS, et al. Genomic landscape of spitzoid neoplasms impacting patient management. Front Med (Lausanne) 2018;5:344. 
Supplemental online content for:

\section{Analysis of Sentinel Node Biopsy and Clinicopathologic Features as Prognostic Factors in Patients With Atypical Melanocytic Tumors}

Andrea Maurichi, MD; Rosalba Miceli, PhD; Roberto Patuzzo, MD; Francesco Barretta, PhD; Gianfranco Gallino, MD; Ilaria Mattavelli, MD; Consuelo Barbieri, MD; Andrea Leva, MD; Umberto Cortinovis, MD; Elena Tolomio, MD; Milena Sant, MD; Gianpiero Castelli, MD; Leonardo Zichichi, MD; Giovanni Pellacani, MD; Ignazio Stanganelli, MD; Marco Simonacci, MD; Ausilia Manganoni, MD; Corrado Del Forno, MD; Gioachino Caresana, MD; Catherine Harwood, MD; Daniele Bergamaschi, PhD; Konstantinos Lasithiotakis, MD; Dorothy Bennett, PhD; Vittoria Espeli, MD; Cristina Mangas, MD; Sandra Leoni Parvex, MD; Barbara Valeri, MD; Mara Cossa, MD; Marta Barisella, MD; Alessandro Pellegrinelli, MD; Claudia Miranda, MD; Andrea Anichini, PhD; Roberta Mortarini, PhD; Odysseas Zoras, MD; and Mario Santinami, MD

J Natl Compr Canc Netw 2020;18(10):1327-1336

eFigure 1: Kaplan-Meier curves for (A) OS and (B) PFS according to sentinel node biopsy result (positive or negative) eFigure 2: Unweighted and weighted Kaplan-Meier curves for OS and PFS According to Complete Dissection eTable 1: Clinicopathologic Characteristics of Patients With Atypical Melanocytic Tumors According to Sentinel Node Status

eTable 2: Clinicopathologic Characteristics of Patients With Positive SN According to CLND, Before and After Propensity Score Weighting

eAppendix 1: Statistical Methods 
A

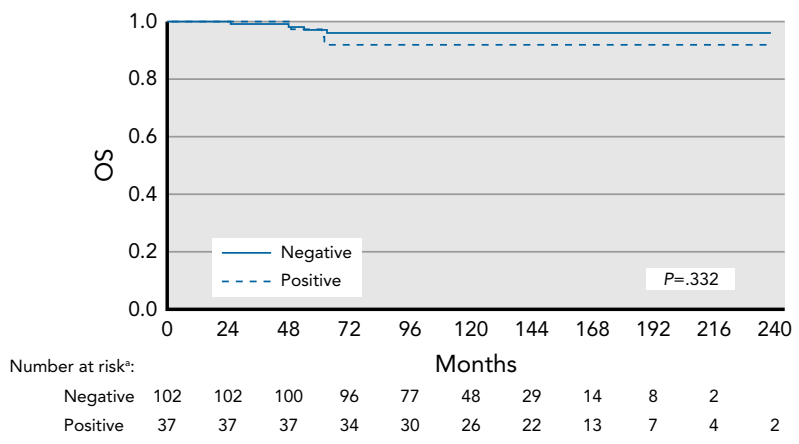

B

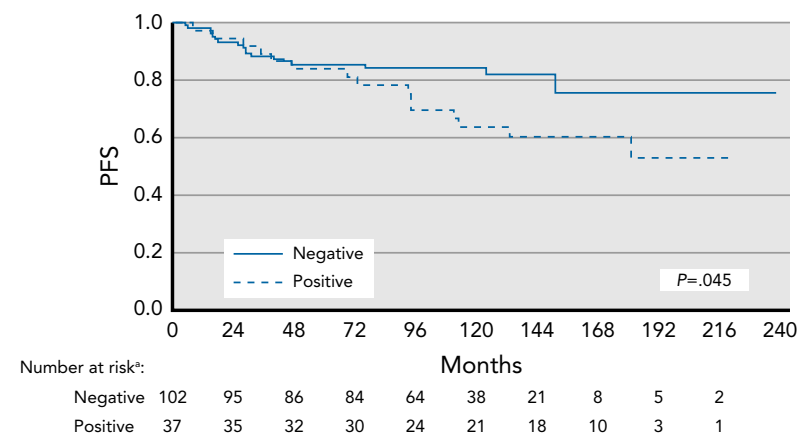

eFigure 1. Kaplan-Meier curves for (A) OS and (B) PFS according to sentinel node biopsy result (positive or negative).

aNumber of patients at risk of an event.

Abbreviations: OS, overall survival; PFS, progression-free survival.

A

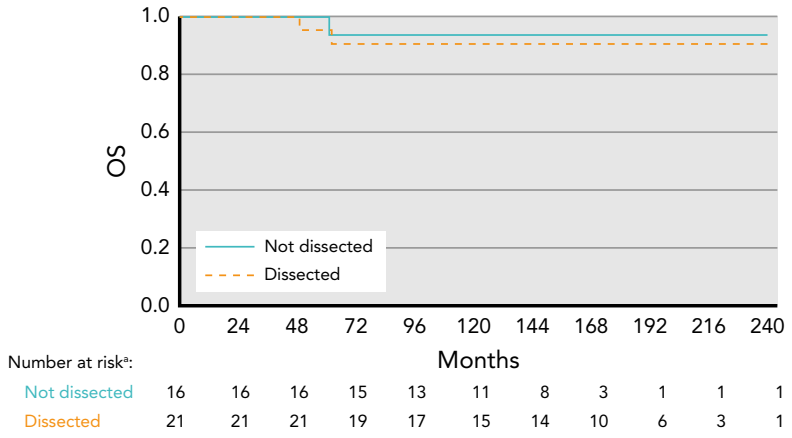

C

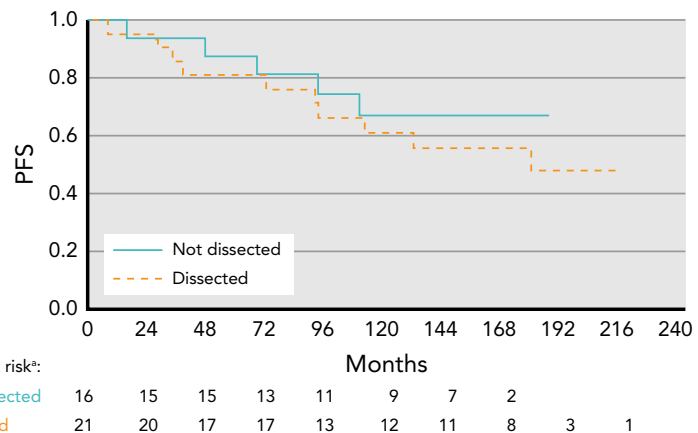

B

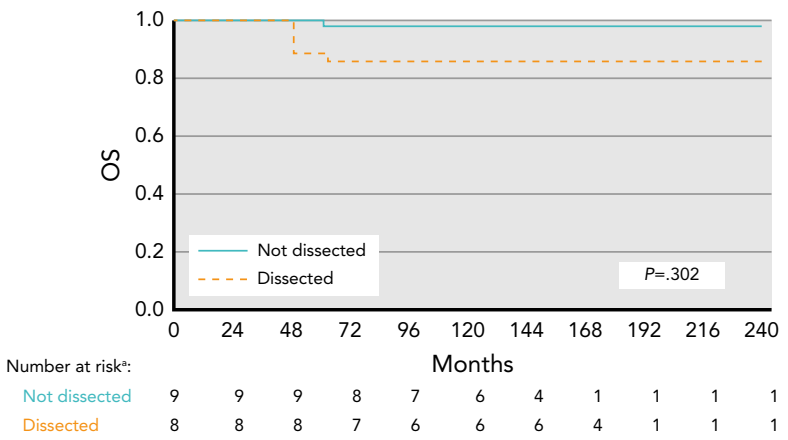

D

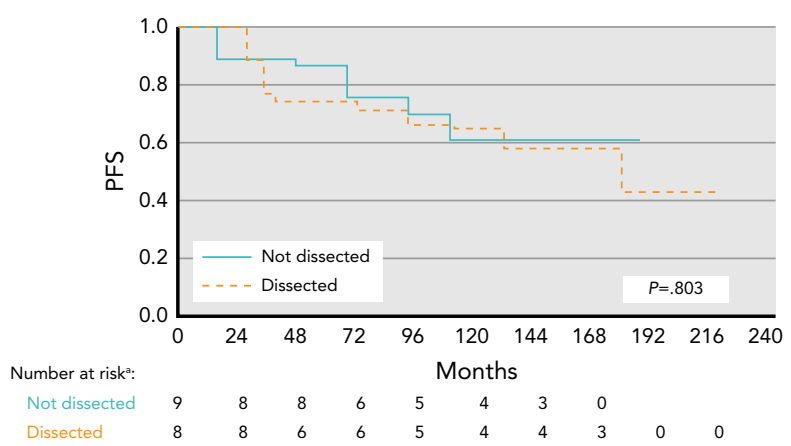

eFigure 2. Unweighted and weighted Kaplan-Meier curves for (A, B) OS, and (C, D) PFS according to complete dissection (performed or not performed).

aWeighted number of patients at risk of an event (rounded to the integer in the weighted analysis).

Abbreviations: OS, overall survival; PFS, progression-free survival. 
eTable 1. Clinicopathologic Characteristics of Patients With AMT According to SN Status

\begin{tabular}{|c|c|c|c|}
\hline & $\begin{array}{c}\text { SN-Negative } \\
\text { n (\%) }\end{array}$ & $\begin{array}{l}\text { SN-Positive } \\
\text { n (\%) }\end{array}$ & SMD \\
\hline Total & $102(73.4)$ & $37(26.6)$ & \\
\hline Age & & & 0.137 \\
\hline$\leq 10 y$ & $6(5.9)$ & $2(5.4)$ & \\
\hline $11-20 y$ & $23(22.5)$ & $9(24.3)$ & \\
\hline$>20 y$ & $73(71.6)$ & $26(70.3)$ & \\
\hline Sex & & & 0.425 \\
\hline Female & $54(52.9)$ & $17(45.9)$ & \\
\hline Male & $48(47.1)$ & $20(54.1)$ & \\
\hline Tumor site & & & 0.328 \\
\hline Head and neck & $34(33.3)$ & $10(27.0)$ & \\
\hline Upper limbs & $19(18.6)$ & $7(18.9)$ & \\
\hline Trunk & $12(11.8)$ & $4(10.8)$ & \\
\hline Lower limbs & $37(36.3)$ & $16(43.2)$ & \\
\hline Histologic subtype & & & 0.190 \\
\hline Spitzoid & $24(23.5)$ & $10(27.0)$ & \\
\hline Nonspitzoida & 78 (76.5) & $27(73.0)$ & \\
\hline Tumor thickness, mm & & & 0.471 \\
\hline Median (IQRE) & $2.36(2.25-2.51)$ & $2.34(2.15-2.40)$ & \\
\hline Ulceration & & & 0.413 \\
\hline Absent & $95(93.1)$ & $36(97.3)$ & \\
\hline Present & $7(6.9)$ & $1(2.7)$ & \\
\hline Mitoses per $\mathrm{mm}^{2}$ & & & 1.946 \\
\hline Median (IQRE) & $2(1-2)$ & $5(4-6)$ & \\
\hline Mitosis at the base of the les & ion & & 2.062 \\
\hline Absent & $87(85.3)$ & $5(13.5)$ & \\
\hline Present & $15(14.7)$ & $32(86.5)$ & \\
\hline Lymphovascular invasion & & & 1.733 \\
\hline Absent & $91(89.2)$ & $9(24.3)$ & \\
\hline Present & $11(10.8)$ & $28(75.7)$ & \\
\hline Tumor-infiltrating lymphocyte & & & 0.017 \\
\hline Absent & $33(32.3)$ & $12(32.4)$ & \\
\hline Brisk & $37(36.3)$ & $13(35.1)$ & \\
\hline Non brisk & $32(31.4)$ & $12(32.4)$ & \\
\hline FISH test $6 p 25$ & & & 0.002 \\
\hline Negative & $88(86.3)$ & $32(86.5)$ & \\
\hline Positive & $14(13.7)$ & $5(13.5)$ & \\
\hline FISH test $6 q 23 / \mathrm{Cep} 6$ & & & 0.023 \\
\hline Negative & $99(97.1)$ & $36(97.3)$ & \\
\hline Positive & $3(2.9)$ & $1(2.7)$ & \\
\hline \multicolumn{4}{|l|}{ FISH test $6 p 25 /$ Cep 6} \\
\hline Negative & $100(98.0)$ & $36(97.3)$ & 0.046 \\
\hline Positive & $2(2.0)$ & $1(2.7)$ & \\
\hline
\end{tabular}

(continued)
eTable 1. Clinicopathologic Characteristics of Patients With AMT According to SN Status (cont.)

\begin{tabular}{|lccc|}
\hline & $\begin{array}{c}\text { SN-Negative } \\
\mathbf{n}(\%)\end{array}$ & $\begin{array}{c}\text { SN-Positive } \\
\mathbf{n}(\%)\end{array}$ & SMD \\
\hline $\begin{array}{l}\text { FISH test 11q13 } \\
\text { Negative }\end{array}$ & $32(86.5)$ & 0.157 \\
\hline $\begin{array}{l}\text { Positive } \\
\text { FISH test 9p21 }\end{array}$ & $12(11.8)$ & $5(13.5)$ & \\
\hline $\begin{array}{l}\text { Negative } \\
\text { Positive }\end{array}$ & $72(70.6)$ & $20(54.1)$ & \\
\hline $\begin{array}{l}\text { FISH test 8q24 } \\
\text { Negative }\end{array}$ & $30(29.4)$ & $17(45.9)$ & \\
\hline Positive & $101(99.0)$ & $36(97.3)$ & \\
\hline
\end{tabular}

aNevoid, deep penetrating nevus, or atypical blue nevus.

Abbreviations: AMT, atypical melanocytic tumor; FISH, fluorescence in situ hybridization; IQRE, interquartile range extremes; SMD, standardized mean difference; SN, sentinel node. 


\section{eTable 2. Clinicopathologic Characteristics of Patients With Positive SN According to CLND, Before and} After Propensity Score Weighting

\begin{tabular}{|c|c|c|c|c|c|c|}
\hline & \multicolumn{3}{|c|}{ Unweighted Statistics } & \multicolumn{3}{|c|}{ Weighted Statistics } \\
\hline & $\begin{array}{c}\text { No CLND } \\
\text { n (\%) }\end{array}$ & $\begin{array}{l}\text { CLND } \\
\text { n (\%) }\end{array}$ & SMD & $\begin{array}{c}\text { No CLND } \\
\text { n (\%) }\end{array}$ & $\begin{array}{l}\text { CLND } \\
\text { n (\%) }\end{array}$ & SMD \\
\hline Age & & & 1.413 & & & 1.637 \\
\hline$\leq 10 y$ & $1(6.3)$ & $1(4.8)$ & & $1.7(19.0)$ & $0(0.3)$ & \\
\hline$>20 y$ & $8(50.0)$ & $18(85.7)$ & & $5.1(56.5)$ & $8.1(92.9)$ & \\
\hline Sex & & & 0.048 & & & 0.057 \\
\hline Female & $7(43.7)$ & $10(47.6)$ & & $4.3(47.6)$ & $4.4(50.5)$ & \\
\hline Male & $9(56.3)$ & $11(52.4)$ & & $4.7(52.4)$ & $4.3(49.5)$ & \\
\hline Tumor site & & & 0.966 & & & 0.874 \\
\hline Lower limbs & $8(50.0)$ & $8(38.1)$ & & $4.3(47.6)$ & $3(34)$ & \\
\hline Histologic subtype & & & 0.872 & & & 0.177 \\
\hline Spitzoid & $2(12.5)$ & $8(38.1)$ & & $1.3(14.6)$ & $1.5(17.4)$ & \\
\hline Nonspitzoida & $14(87.5)$ & $13(61.9)$ & & $7.7(85.4)$ & $7.2(82.6)$ & \\
\hline Tumor thickness, mm & & & 0.047 & & & 0.035 \\
\hline Median (IQRE) & $2.39(2.20-2.40)$ & $2.3(2.12-2.36)$ & & $2.31(2.08-2.40)$ & $2.35(2.17-2.38)$ & \\
\hline Ulceration & & & $<0.001$ & & & $<0.001$ \\
\hline Absent & $16(100)$ & $20(95.2)$ & & $9(100)$ & $8.2(96.8)$ & \\
\hline Present & $0(0)$ & $1(4.8)$ & & $0(0)$ & $0.5(3.2)$ & \\
\hline Absent & $2(12.5)$ & $7(33.3)$ & & $1.3(14.8)$ & $1.1(13.1)$ & \\
\hline Present & $14(87.5)$ & $14(66.7)$ & & $7.7(85.2)$ & $7.6(86.9)$ & \\
\hline Tumor-infiltrating lymphocytes & & & 0.675 & & & 0.739 \\
\hline Absent & $5(31.2)$ & $7(33.3)$ & & $2.4(26.4)$ & $4.1(46.6)$ & \\
\hline Brisk & $4(25.0)$ & $9(42.9)$ & & $5.2(58.2)$ & $3.8(44.7)$ & \\
\hline Non brisk & $7(43.8)$ & $5(23.8)$ & & $1.4(15.4)$ & $0.8(8.7)$ & \\
\hline FISH test $6 p 25$ & & & 0.183 & & & 0.410 \\
\hline Negative & $14(87.5)$ & $18(85.7)$ & & $5(55.4)$ & $5.3(60.8)$ & \\
\hline Positive & $2(12.5)$ & $3(14.3)$ & & $4(44.6)$ & $3.4(39.2)$ & \\
\hline FISH test $6 q 23 / \mathrm{Cep} 6$ & & & $<0.001$ & & & $<0.001$ \\
\hline Negative & $16(100)$ & $20(95.2)$ & & $9(100)$ & $8.2(96.8)$ & \\
\hline Positive & $0(0)$ & $1(4.8)$ & & $0(0)$ & $0.5(3.2)$ & \\
\hline FISH test $6 p 25 /$ Cep 6 & & & $<0.001$ & & & $<0.001$ \\
\hline Negative & $16(100)$ & $20(95.2)$ & & $9(100)$ & $8.2(96.8)$ & \\
\hline Positive & $0(0)$ & $1(4.8)$ & & $0(0)$ & $0.5(3.2)$ & \\
\hline
\end{tabular}


eTable 2. Clinicopathologic Characteristics of Patients With Positive SN According to CLND, Before and After Propensity Score Weighting (cont.)

\begin{tabular}{|c|c|c|c|c|c|c|}
\hline & \multicolumn{3}{|c|}{ Unweighted Statistics } & \multicolumn{3}{|c|}{ Weighted Statistics } \\
\hline Negative & $14(87.5)$ & $18(85.7)$ & & $5(55.4)$ & $5.3(60.8)$ & \\
\hline Positive & $2(12.5)$ & $3(14.3)$ & & $4(44.6)$ & $3.4(39.2)$ & \\
\hline Negative & $8(50.0)$ & $12(57.1)$ & & $5.3(58.4)$ & $5.5(62.4)$ & \\
\hline Positive & $8(50.0)$ & $9(42.9)$ & & $3.7(41.6)$ & $3.2(37.6)$ & \\
\hline FISH test $8 q 24$ & & & $<0.001$ & & & $<0.001$ \\
\hline Negative & $16(100)$ & $20(95.2)$ & & $9(100)$ & $8.2(96.8)$ & \\
\hline Positive & $0(0)$ & $1(4.8)$ & & $0(0)$ & $0.5(3.2)$ & \\
\hline
\end{tabular}

aNevoid, deep penetrating nevus, or atypical blue nevus.

Abbreviations: CLND, completion lymph node dissection; FISH, fluorescence in sit hybridization; IQRE, interquartile range extremes; SMD, standardized mean difference; $\mathrm{SN}$, sentinel node. 


\section{eAppendix 1. Statistical Methods}

\section{Survival Outcome Definitions}

Overall survival (OS) was defined as the time from diagnosis to death from any cause; time was censored at the latest follow-up for patients still alive. Progression-free survival (PFS) was defined as the time between tumor diagnosis and the first event (regional nodal and/or in-transit metastases, distant metastases) or death, whichever occurred first; time was censored at the date of last follow-up for alive and event-free patients. Median follow-up was calculated with the reverse Kaplan-Meier method using OS data. ${ }^{1}$

\section{Inverse Probability Treatment Weighting and Balance Assessment}

When a direct comparison was feasible (ie, when the compared groups did not consist of selected patients as in the SNBpositive vs SNB-negative comparison), the curves were estimated using the Kaplan-Meier method and compared using the log-rank test. Inverse probability treatment weighting (IPTW) ${ }^{2}$ based on the propensity score (PS) method was used to balance the comparison between groups. The covariates included in the logistic model for PS estimation were tumor thickness, mitotic rate $/ \mathrm{mm}^{2}$, ulceration, lymphovascular invasion (LVI), mitosis at the base of the lesion, spitzoid histology, and 9p21 loss and 11q13 gain as determined by fluorescence in situ hybridization (FISH). The standardized mean difference (SMD) ${ }^{3}$ was used to evaluate the unbalanced and balanced clinicopathologic characteristics of patients with atypical melanocytic tumors (AMT). SMDs $\geq 0.3$ were considered indicative of a relevant between-group imbalance.

\section{Association Analyses}

We studied the binary association between all investigated covariates by evaluating the Spearman correlation coefficients, and the association between PFS and all investigated covariates by means of univariable Cox models. Subgroup analyses were performed in patients who underwent sentinel node biopsy. We applied Firth's penalized method to obtain hazard ratio estimates in sparse samples. ${ }^{4}$ Mitotic rate, age, and tumor thickness were modeled as continuous variables using a 3-knot restricted cubic spline to obtain a flexible fit. ${ }^{5}$ The small number of events precluded statistical modeling on OS.

\section{Variable Selection Method}

The elastic net penalization method is a combination of the ridge and lasso penalties, sharing with the latter the ability to set some coefficient estimates to zero but distributing the weight to more features, so that the elastic net tends to select more features.

We considered a statistical test significant when the corresponding $P$ value was $<.05$. Statistical analyses were performed using SAS version 9.2 (SAS Institute Inc) and R software 2018 (R Foundation for Statistical Computing).

\section{References}

1. Schemper M, Smith TL. A note on quantifying follow-up in studies of failure time. Control Clin Trials 1996;17:343-346.

2. Austin PC, Stuart EA. Moving towards best practice when using inverse probability of treatment weighting (IPTW) using the propensity score to estimate causal treatment effects in observational studies. Stat Med 2015; 34:3661-3679
3. Flury BK, Riedwyl $\mathrm{H}$. Standard distance in univariate and multivariate analysis. Am Stat 1986;40:249-251.

4. Heinze G, Dunkler D. Avoiding infinite estimates of time-dependent effects in small-sample survival studies. Stat Med 2008;27:6455-6469.

5. Durrleman S, Simon R. Flexible regression models with cubic splines. Stat Med 1989;8:551-561. 